\title{
Conocimientos y percepción de riesgo sobre el Sida en estudiantes de bachillerato de una universidad pública de Yucatán, México: un abordaje cuantitativo-cualitativo.
}

Artículo Original

Ligia Vera-Gamboa, Francisco Sánchez-Magallón, Renán A. Góngora-Biachi.

Centro de Investigaciones Regionales “Dr. Hideyo Noguchi”, Universidad Autónoma de Yucatán, Mérida, Yucatán, México.

\section{RESUMEN.}

Introducción. La mitad de las nuevas infecciones por el virus de la inmunodeficiencia humana (VIH) ocurren en jóvenes de 15 a 24 años. Yucatán, México es tercer lugar nacional por tasa de incidencia de Sida y los casos juveniles representaban el 15\% en 2005.

Objetivos. Determinar los conocimientos, actitudes y percepción de riesgo ante el Sida y explorar las habilidades para la prevención, en estudiantes de preparatoria de una universidad pública en Yucatán, México.

Material y métodos. Durante el ciclo escolar 20032004, se aplicó un cuestionario con 40 preguntas sobre conocimientos y actitudes ante la infección por VIH en 210 estudiantes. Posteriormente, se conformaron 9 grupos focales para conocer la percepción de riesgo y las habilidades de prevención utilizando un guión de entrevista

Resultados. A nivel cuantitativo, encontramos conocimientos adecuados sobre Sida en el $98 \%$ de los resultados. En lo cualitativo, señalaron como factores de riesgo la falta de información acerca del Sida, la sexualidad y la invulnerabilidad. Reconocen también la presión social de pares como factor para que continúen infectándose. Aun cuando consideran que podrían infectarse, estiman que esto sería por mecanismos diferentes de las prácticas sexuales. Sugirieron para mejorar la prevención más campañas de prevención, eliminar el machismo en la vida diaria, así como la educación de pares.

Conclusiones. Los jóvenes cuentan con información sobre el Sida, pero la falta de percepción de riesgo obstaculiza la labor de prevención. Están presentes los estereotipos de género acerca de la sexualidad. Consideran la educación de pares como la mejor manera para recibir información sobre el VIH/Sida.

(Rev Biomed 2006; 17:157-168)

Palabras clave: Conocimientos, percepción de riesgo, Sida, estudiantes, Yucatán, México.

Solicitud de sobretiros: M.C. Ligia Vera-Gamboa, Centro de Investigaciones Regionales “Dr. Hideyo Noguchi”, Universidad Autónoma de Yucatán, Calle 59 No. 490 x Av. Itzáes, Centro, C.P. 97000, Mérida, Yucatán, México. Correo electrónico: vgamboa@uady.mx 


\section{Vera-Gamboa, F Sánchez-Magallón, RA Góngora-Biachi}

\section{SUMMARY.}

Knowledge and risk perception about AIDS among high school students in a public university of Yucatan, Mexico: a quantitavequalitative approach.

Introduction. Half of the new Human Immunodeficiency Virus (HIV) infections occur among young people, 15 to 24 years old. The State of Yucatán, Mexico is in the third place in the country according to its incidence rate of AIDS, and the cases in young people represented $15 \%$ in 2005.

Objectives. To determine the knowledge, attitudes, and risk perception about AIDS and to explore abilities for prevention among high school students in a public university of Yucatan, Mexico.

Material and methods. During the 2003-2004 school year, a questionnaire with forty items about knowledge and attitudes about HIV infection was applied to 210 students. Then, nine focal groups were made to investigate the risk perception and the abilities for prevention, using an interview script.

Results. At a quantitative level, we found appropriate knowledge in relation to AIDS in 98\% of the participants. In the qualitative aspects the students reported lack of information about AIDS, sexuality, and invulnerability as a risk factor. They admitted that social pressure by peers is a factor for infection. They considered that if they ever suffered from an HIV infection the mechanisms of transmission would be different from sexual activity. They suggested improving prevention campaigns, to eliminate male chauvinism, and to promote education by peers.

Conclusions. Young people know about AIDS, but the abscence of risk perception is an obstacle for prevention. Gender stereotypes about sexuality are present. These students considered that education by peers is the best way to receive information about AIDS. (Rev Biomed 2006; 17:157-168)

Key words: Knowledge, risk perception, AIDS, students, Yucatan, Mexico.

\section{INTRODUCCIÓN.}

Entre las situaciones que enfrentan los adolescentes, cuando existe carencia de información sexual, se encuentran los embarazos no deseados ni programados y las infecciones de transmisión sexual (ITS), entre otras. Según datos de la Organización Mundial de la Salud (OMS), diariamente ocurren en el mundo 100 millones de relaciones sexuales, de las cuales alrededor de un millón terminan en embarazos no deseados y cerca de medio millón en alguna ITS (1). De las ITS, la más devastadora es, sin duda, la infección por el Virus de Inmunodeficiencia Humana (VIH).

En Yucatán, México, se han realizado diversos estudios en jóvenes estudiantes de preparatoria que reportan que el 23\% ya había iniciado relaciones sexuales (2). La edad promedio del debut sexual fue entre los 15 y 16 años, y en los jóvenes del área rural entre los 14 y 15 años (2). Flores-Galaz (3) reportó en 2001 en un grupo de estudiantes universitarios, que el 43\% de ellos ya había tenido relaciones a una edad promedio de 17.8 años.

El Síndrome de Inmunodeficiencia Adquirida (Sida), es uno de los más graves y principales problemas médicos en la actualidad, al considerar su trascendencia y magnitud. Del año 2000 (4) al 2003 (5), ONUSIDA ha venido reportando la cifra cercana a cinco millones de nuevas infecciones anuales. Se conoce también que el 95\% de estas nuevas infecciones ocurren por contacto sexual no protegido, presentándose más de la mitad de ellas en países en vías de desarrollo (6).

De acuerdo con la OMS, cerca de la mitad de las nuevas infecciones ocurren en personas de 15 a 25 años (5). Sin embargo, considerando el largo período de latencia de la enfermedad, se supone que el 31.5\% de los casos notificados adquirieron el virus en el período de la adolescencia y 37.8\% lo hicieron en la segunda década de vida $(7,8)$.

A nivel nacional, al momento del presente estudio, Yucatán ocupaba el quinto lugar por tasa de incidencia de Sida (9) y para fines de 2004 había ascendido al tercer lugar por tasa de incidencia (10). Del total de casos registrados hasta fines de

\section{Revista Biomédica}




\section{Conocimientos y percepción de riesgo sobre el Sida en estudiantes}

2004, el 15\% corresponde a jóvenes de 15 a 24 años, cifra superior al 3\% que representaban para 1989. De estos, el 93.6\% adquirió la infección por VIH a través de relaciones sexuales desprotegidas (Servicios de Salud de Yucatán, 2003).

Los objetivos del presente trabajo fueron evaluar los conocimientos y actitudes, así como explorar la percepción de riesgo y las habilidades para la prevención y auto-cuidado de la salud, en relación a la epidemia del VIH/Sida, en estudiantes de bachillerato de una Universidad pública en Mérida, Yucatán, México.

\section{MATERIAL Y MÉTODOS.}

Estudio descriptivo, exploratorio, de corte cuantitativo-cualitativo realizado de enero a mayo de 2004.

Se eligió una escuela preparatoria de la Universidad pública del estado de Yucatán, ya que asisten a ella jóvenes de diversos estratos socioeconómicos, lo que daría representatividad a la muestra de los jóvenes de ese rango de edad. La muestra fue calculada en función del total de estudiantes matriculados $(3,722)$ en el ciclo escolar 2003-2004, una prevalencia de infección de VIH en jóvenes de $8 \%$ y un nivel de confianza del $95 \%$, quedando conformada por 210 estudiantes, los cuales fueron seleccionados por sistema de tómbola. A todos ellos se les aplicó un cuestionario sobre conocimientos y actitudes ante el Sida validado por Castro-Sansores y col. (11).

Para el aspecto cualitativo, de estos 210 estudiantes, se eligieron de manera aleatoria 72 para la realización de una entrevista, siguiendo un guión previamente estableciendo, a través de la técnica de grupos focales. Lo anterior con la finalidad de indagar de manera más profunda los conocimientos, actitudes y percepción de riesgo desde la narrativa de los jóvenes. Se eligió la estrategia de grupos focales porque permite descubrir la lógica argumentativa que utilizan las personas en relación con el problema de estudio, y al mismo tiempo permite al investigador observar a varios actores sociales interaccionando y elaborando en esa interacción los significados sociales adscritos al tema de estudio, en este caso, la infección por el VIH y el Sida $(12,13)$.

Previa autorización de las autoridades escolares y los padres de familia, se procedió a la aplicación del cuestionario y las entrevistas a los grupos focales. Posterior a cada sesión de los grupos focales, se proporcionó información sobre la temática respondiendo a las dudas e inquietudes sobre el VIH/Sida.

La información cuantitativa obtenida se analizó a través de estadística descriptiva utilizando el programa SPSS v. 11.0 . La información cualitativa fue transcrita para su análisis. Respuestas similares fueron agrupadas para establecer las categorías de análisis y determinar las ideas principales surgidas en las sesiones.

\section{RESULTADOS.}

Se aplicó el cuestionario a los 210 estudiantes previstos, de los cuales $44 \%$ fueron del sexo masculino y los restantes (56\%) del sexo femenino. La edad promedio de los entrevistados fue de 16 años (intervalo 14-19 años). La información acerca del Sida fue dividida en tres grandes apartados: conocimientos generales, mecanismos de transmisión y medidas preventivas.

\section{Conocimientos generales sobre el Sida.}

Respecto a los conocimientos generales sobre el Sida (5 reactivos), el 98\% (206/210) contaban con suficiente y adecuada información sobre las generalidades de la infección por VIH (figura 1). El 95\% de los jóvenes conoce el significado de las siglas de Sida y reconoció al VIH como el agente causal. Todos ellos admitieron que el VIH es capaz de infectar a cualquier persona, 98\% sabía que es una enfermedad que destruye las defensas de una persona y $99.5 \%$ sabía que es una enfermedad incurable y mortal.

\section{Mecanismos de transmisión.}

El total de los encuestados (210) manifestó saber cómo se transmite el SIDA. Sin embargo, 


\section{Vera-Gamboa, F Sánchez-Magallón, RA Góngora-Biachi}

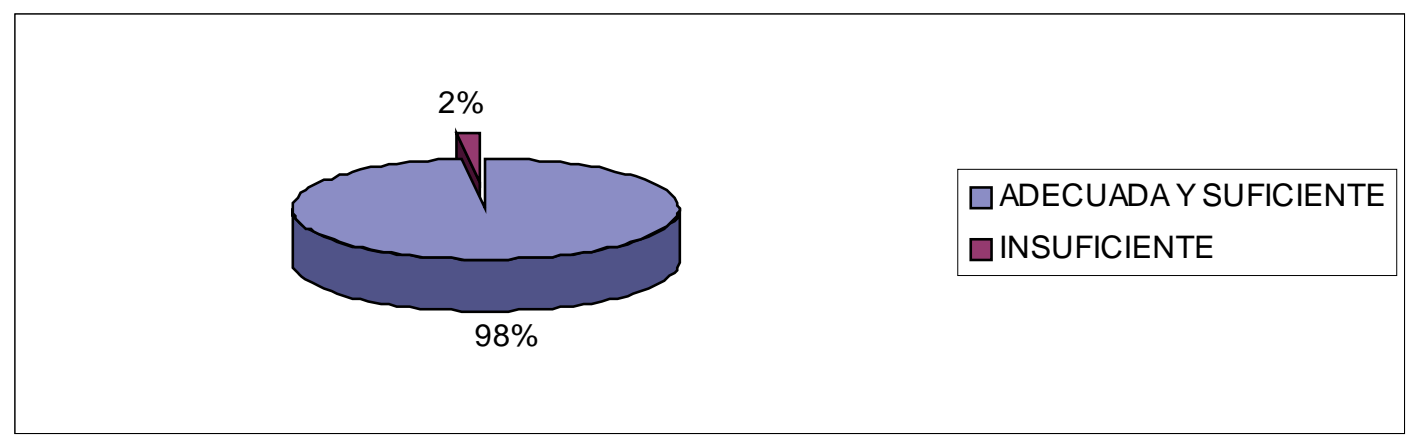

NOTA.- Se consideró conocimiento adecuado si respondió con certeza como mínimo 3 de 5 reactivos.

Figura 1.- Información general sobre VIH/Sida en estudiantes de la preparatoria dos de la Universidad Autónoma de Yucatán $(n=210)$.

18 (9\%) tenían ideas erróneas o refirieron no saber sobre los mecanismos de transmisión del VIH.

Así, en lo que respecta a los mecanismos de transmisión se encontró que el $21.4 \%$ de los encuestados no considera el sexo oral como mecanismo de transmisión para el VIH. Un porcentaje similar refirió no saber si por esta vía se podría infectar. Al cuestionarlos sobre si una persona mordida por otra infectada por VIH se podía infectar, 52 (24.8\%) refirieron que sí.

Respecto a la infección por VIH a través de picadura de mosquitos, 36 (17.1\%) respondieron que sí y 35 (16.7\%) no sabían. Ambos porcentajes totalizan la tercera parte de los encuestados (33.8\%).

Dos estudiantes (1\%) dijeron que la infección por VIH se puede transmitir por contacto casual (saludo) y otros dos (1\%) creen que se pueden infectar por el VIH por estar en la misma clase que una persona infectada.

El 5\% (10) respondió que una persona se puede infectar por usar sanitarios públicos, beber de fuentes públicas, bañarse en piscina o compartir un sándwich o una bebida con una persona infectada y 23 (11\%) no sabían si estas conductas podían favorecer la transmisión de la infección.

En cuanto a la transmisión perinatal, 5 jóvenes (2.4\%) dijeron que una madre no podía contagiar a su bebe durante el embarazo y 6 (2.9\%) respondieron que no sabían.

\section{Revista Biomédica}

\section{Medidas de prevención.}

En cuanto a las medidas de prevención, 4 (2\%) respondieron desconocer cómo se previene la infección por VIH. Sin embargo, 30 (12.6\%) jóvenes tenían ideas erróneas o no sabían acerca de las formas de prevención para la infección por el VIH.

La abstinencia fue considerada como preventivo por 184 (87.6\%) jóvenes. El uso del condón y la fidelidad fueron las medidas de prevención más mencionadas por los adolescentes (figura 2). En lo que respecta al sexo seguro (prácticas sexuales sin llegar al coito), no fue considerada como una medida eficaz por 83 jóvenes (39.5\%) y 24 (11.4\%) no sabían. También fueron señaladas como medidas preventivas por estos jóvenes estudiantes el uso de sangre segura (182 entrevistados, 86.7\%) y evitar el uso de drogas (184 entrevistados, 87.6\%).

\section{Actitudes frente al Sida.}

La mayoría de los encuestados 208 (99\%) manifestó que sí se debía enseñar lo referente al Sida en las escuelas.

Al preguntar si se debe permitir que un estudiante con VIH/Sida asista a clases, 200 (95.2\%) de los encuestados respondió afirmativamente y 5 entrevistados (2.4\%) en cada caso dijeron que no o que no sabían. Acerca de si les molestaría estar en la misma clase que un estudiante con VIH/Sida, 176 estudiantes (83.8\%) respondieron que no y 9 (4.3\%) dijeron que sí les 


\section{Conocimientos y percepción de riesgo sobre el Sida en estudiantes}

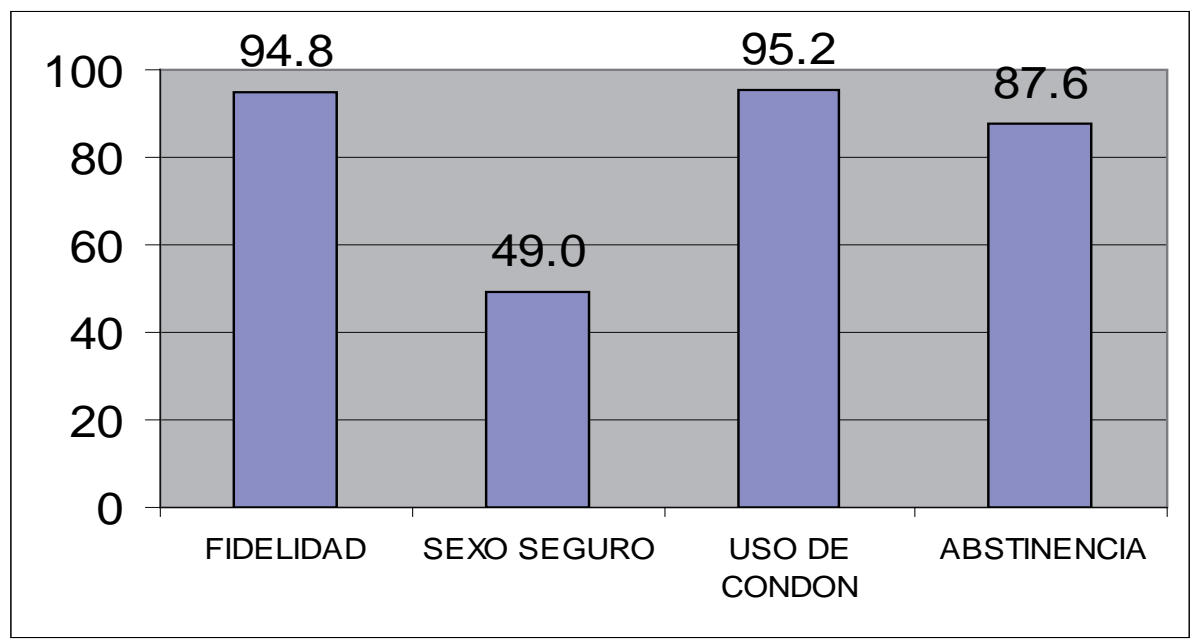

Figura 2.- Medidas para la prevención de la infección por el VIH (en porcentaje) consideradas por los estudiantes de la preparatoria dos de la Universidad Autónoma de Yucatán (n=210).

molestaría. Situación similar se presentó ante el hecho de que si las personas infectadas por el VIH debían ser consideradas culpables de haberse infectado, 176 (83.8\%) contestaron que no y 13 (6.2\%) dijeron que sí.

Por otra parte, el 5.7\% (12) consideran que el tratamiento para las personas viviendo con VIH/Sida es una pérdida de tiempo y dinero y 10.5\%,(22) dijeron no saber. Se preguntó que, si en el caso de estar ellos infectados, quisieran que alguien se enterara, 81 (38.6\%) dijeron que no y 68 (32.4\%) dijeron que sí. La mayoría de los adolescentes encuestados manifestaron actitudes favorables para las personas infectadas por VIH (figura 3).

\section{Comportamiento sexual.}

De los 210 jóvenes encuestados, 33 (15.7\%) ya había tenido relaciones sexuales (17 del sexo femenino y 16 del sexo masculino). La edad de inicio de vida sexual fue entre los 16 y 18 años para las mujeres y entre 15 y 19 años para los varones.

De los varones con vida sexual, 15 refirieron haber tenido relaciones con mujeres y uno con hombres y mujeres. En el caso de las mujeres, una refirió relaciones con una pareja casual femenina.

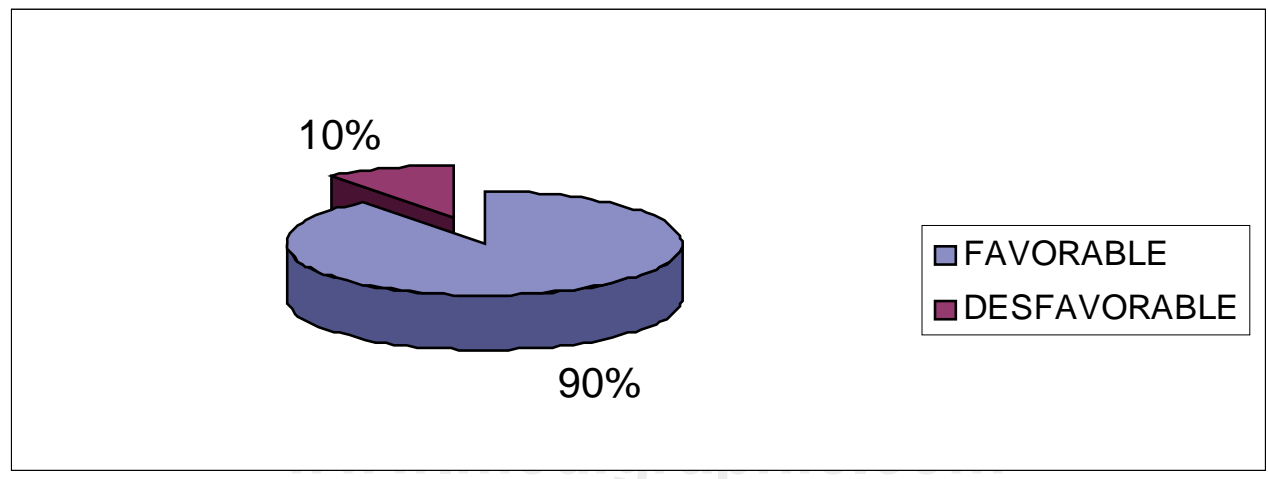

NOTA.- Se consideró actitud favorable a las respuestas de los encuestados que coincidían en no rechazar y apoyar a las personas infectadas con VIH.

Figura 3.- Actitud ante la infección por VIH de estudiantes de preparatoria de Mérida, Yucatán, México $(n=210)$. 
L Vera-Gamboa, F Sánchez-Magallón, RA Góngora-Biachi

Cuadro 1.- Comportamiento sexual en el último mes en estudiantes de preparatoria en Mérida, Yucatán, México.

\begin{tabular}{|c|c|c|c|c|c|}
\hline & AMIGA(O) & NOVIA(O) & $\begin{array}{c}\text { AMIGA(O) Y } \\
\text { NOVIA(O) }\end{array}$ & DESCONOCIDA & TOTAL \\
\hline MASCULINO & $6(2.9 \%)$ & $4(1.9 \%)$ & $2(1.0 \%)$ & $1(0.5 \%)$ & $13(6.2 \%)$ \\
\hline FEMENINO & $4(1.9 \%)$ & $11(5.3 \%)$ & --- & $1(0.5 \%)$ & $16(7.7 \%)$ \\
\hline
\end{tabular}

En el cuadro 1 se puede observar el tipo de pareja con quien tuvieron relaciones en el mes previo al estudio. De todos los individuos que tuvieron relaciones sexuales, al cuestionarlos sobre el uso del condón, más de la mitad respondió haberlo utilizado en el último mes y anteriormente en otras ocasiones. Se investigó también con que fin usaron el condón (figura 4).

\section{Información cualitativa.}

Se trabajó con nueve grupos focales, (tres de cada año escolar), cada uno con ocho integrantes en igual número de hombres y mujeres. Se transcriben a continuación los hallazgos del estudio.

$¿$ Crees que cualquier persona puede infectarse por el VIH?

Coincidieron en señalar que sí, que cualquier persona puede infectarse, aunque en menor medida prevalece la idea de que es una enfermedad de homosexuales o trabajadoras sexuales. Se transcriben algunas opiniones expresadas por los jóvenes:

"Cuando se activan nuestras hormonas en un mundo que no conocemos, si no tenemos la suficiente información nos podemos contagiar. A mí ni en mi casa ni en la escuela me habían hablado sobre el sida y sexualidad."

"Todos se pueden infectar por VIH, te puedes contagiar aunque sea tu primera vez o por falla o mal uso del condón."

¿Por qué crees que las personas jóvenes se siguen infectando por el VIH, aunque tengan información?

Aunque sesenta y cuatro de los entrevistados afirmaron saber que la enfermedad existe, al igual que el riesgo de infección, por diversas razones consideran que a ellos no les puede pasar, en especial porque no tienen vida sexual activa. Otros opinaron que eso ocurre aún por ignorancia y falta

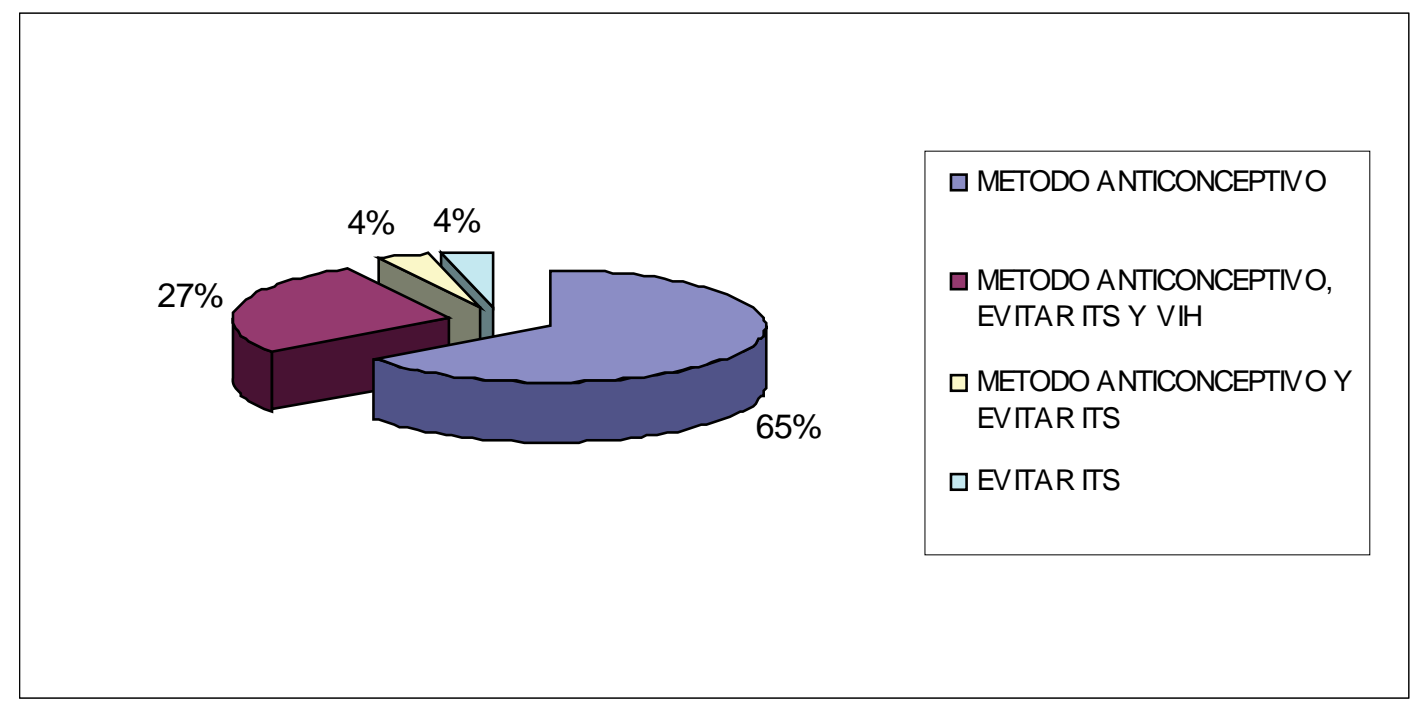

Figura 4.- Finalidad del uso del condón en estudiantes de preparatoria de Mérida, Yucatán, México ( n= 29).

\section{Revista Biomédica}




\section{Conocimientos y percepción de riesgo sobre el Sida en estudiantes}

de información. Al respecto:

"Yo considero que la información que tengo sobre el Sida no es suficiente, y en los medios de comunicación hay información que te bombardea, donde te muestran a personas que tienen sexo sin protección y están con muchas parejas pero nunca te muestran las posibles consecuencias"

"La mayoría de lo que aprendes en la calle no es lo correcto, pero es lo más rápido y cercano y si no te dan información en tu casa o en la escuela te formas una idea errónea."

Igualmente mencionaron que por actuar irresponsablemente y por el sentimiento de invulnerabilidad, los jóvenes se siguen contagiando:

"A esta edad tenemos el complejo de Supermán y nos vale. Hormona mata neurona."

"Por calentura, es difícil resistir la tentación de que es tu primera vez y usar condón."

"Porque no crees en algo hasta que tú lo vives o le pasa a alguien cercano a ti."

"No te imaginas que otro joven tiene Sida o puede ser portador del VIH."

"Estamos en la etapa en que somos aventados y nos gusta experimentar."

Una chica opinó que la responsabilidad de la relación debe ser compartida:

"No debemos dejarle toda la responsabilidad a los chavos, porque también nosotras vamos a participar en ese acto y debemos tomar precauciones."

Con respecto a la presión social que sentían, externaron:

"Le haces más caso a tus amigos que a unos carteles o a la información que ves por la tele."

"Los amigos te impulsan a hacer cosas, por mi casa, el que se acueste con más mujeres o el que conozca más centros nocturnos es mejor, sin saber que realmente es un idiota porque está poniendo en juego su vida."

"A mí, mis padres no me hablaron sobre sexo, lo que sé es por la escuela, porque lo vi en la tele o lo escuché en la calle."

\section{¿Cómo amenaza el SIDA a la población de} jóvenes?

Todos coincidieron en que la infección por VIH es una amenaza para los jóvenes aunque no exclusiva de ellos. La principal forma en que se sienten amenazados es por rechazo social y discriminación o por el hecho de que cualquier persona se puede contagiar y los jóvenes no están exentos. Al respecto un joven comentó:

"Una persona con Sida, aunque quiera realizar su vida normal no puede por la discriminación social y porque tiene que someterse a un tratamiento".

O comentarios como los siguientes:

"Nos imposibilita para lograr nuestras metas y nos pone en desventaja ante los demás." "Se acaba tu vida, si pensabas en estudiar ahora sólo pensarás en sobrevivir."

\section{$¿$ Crees que te puedes contagiar por VIH/ SIDA?}

Casi todos respondieron que sí (70/72) creían que podían infectarse. Algunos comentarios se presentan:

"No, porque no me drogo y no tengo una vida sexual activa."

"No, porque no tengo una vida sexual activa. Por el momento no necesito de intervenciones médicas y evito ponerme en contacto con situaciones de riesgo como acudir a centros nocturnos; además estoy seguro de mis convicciones."

"Sí, porque por donde yo vivo hay muchos tugurios y amigos más grandes siempre me invitan, así es que el riesgo siempre existe."

"Sí, porque cuado tú estas con tu pareja, no sabes si ya ha estado con otras personas y se ha protegido"

"Sí lo creemos pero no lo aceptamos, ese es el problema"

Más de la mitad (56/72) manifestó que le preocupaba el hecho de poderse infectar por el VIH, por todas las repercusiones que conlleva esta infección, como son, discriminación social, 


\section{Vera-Gamboa, F Sánchez-Magallón, RA Góngora-Biachi}

rechazo y, sobre todo, la muerte. Dos varones dijeron no preocuparles por el hecho de estar bien informados y por ser personas lo suficientemente maduras para controlarse y otro comentó estar más preocupado por el hecho de que su novia se embarazara que por el Sida.

Cinco, (tres varones y dos mujeres) dijeron que les preocupaba tanto, que el pensar en infectarse los haría considerar el suicidio. Al respecto comentaron:

"Sí, porque yo le temo muchísimo a la muerte y sé que si me da SIDA me voy a morir. “

"Sí, porque por un momento de placer puedes perder tu vida, no voy a poder formar una familia no voy a tener con quien compartir mi vida. Yo tengo sueños y si me contagio todos mis sueños se van a ver interrumpidos por unos minutos de placer."

"Sí, porque me sentiría culpable y me deprimiría tanto que hasta pensaría en suicidarme."

"A mi sí me preocupa tanto el hecho de poder estar contagiado que pienso que si llego a estar contagiado por VIH, para que espero a que me mate la enfermedad, mejor me mato de una vez."

\section{¿Que te haría sospechar que una persona tiene} la infección por el VIH/Sida?

La mayoría (57/72) estuvo de acuerdo en que una persona infectada por el VIH puede estar asintomática totalmente e incluso ni ella misma saberlo e infectar a otras personas. Algunos(15/72) opinaron que el aspecto físico se deteriora y el paciente queda "flaco", con fiebre, lesiones de la piel, demacrado en general, pero resaltaron que esto ocurría en la etapa terminal de la enfermedad.

\section{¿Qué haces para evitar contraer la infección por VIH?}

Algunos respondieron no hacer nada (55/72), porque no tenían vida sexual activa y no habían considerado la abstinencia sexual como método para prevenir la infección por VIH. Otros (5) respondieron que usaban condón o lo usarían en caso de tener relaciones sexuales. Algunos jóvenes (12/72) sí consideraron la abstinencia y la fidelidad. También dijeron que verifican que el uso de las agujas o las transfusiones se realicen en lugares confiables. Señalaron también no tener amistades con personas que pueden realizar actividades de riesgo y no acudir a centros nocturnos o lugares que los puedan poner en peligro de infección. Al respecto comentaron:

"Yo creo que es tener más conciencia, no presentarte en lugares donde se puede contraer esa enfermedad, no ir a tugurios, usar más la cabeza y ver el noviazgo como una amistad nada más, no drogarme y practicar lo que sé del uso del condón."

"Liberar un poquito más la mente para ir a la farmacia y conseguir un condón. Esos cinco minutos que te tomas para comprar un condón te pueden dar muchos años de vida."

"Con todas las personas con las que he tenido relaciones sexuales, he usado el condón porque el resto de los métodos de planificación no protegen contra el Sida aunque, sin duda, no se siente igual."

\section{¿Que medidas tú consideras eficaces para disminuir el riesgo de VIH?}

Los jóvenes reconocen como eficaces la abstinencia (66/72); uso del condón (57//2) y la fidelidad (35/72). También consideraron otras acciones como preventivas para la infección por el VIH. Las más mencionadas fueron: informarse sobre el tema (40), el uso de agujas estériles (35); transfusión de sangre segura y no exponerse a modas que te pongan en riesgo como los tatuajes y las perforaciones.

\section{¿Qué campañas de prevención de VIH/Sida conoces? \\ La mayoría de los adolescentes (66/72) refirieron no conocer ninguna campaña ni haber estado en contacto directo con una de ellas. \\ En general, mencionaron haber escuchado o}

\section{Revista Biomédica}




\section{Conocimientos y percepción de riesgo sobre el Sida en estudiantes}

visto en la televisión las conocidas como: Telsida, Conasida y lazo rojo, pero dijeron no conocer de qué se tratan ni saber como funcionan. $\mathrm{Al}$ respecto, comentaron:

"Sé que existen, pero yo no conozco ninguna."

"Las campañas de la televisión que dicen que te protejas usando condón.”

"Telsida para informarte sobre el SIDA, puede que haya muchas pero no son conocidas." "Telsida, Conasida, aunque realmente no las conocemos. Sólo las hemos escuchado o visto en la tele, pero no sabemos de qué tratan."

\section{¿De qué modo crees que se pueda mejorar la prevención del VIH/Sida en los jóvenes?}

Todos los entrevistados coincidieron en que dar suficiente y adecuada información haría que los adolescentes crearan conciencia sobre la seriedad del asunto. Además, esto tendría que estar acompañado de más y mejores campañas de prevención.

"Es cosa de que cada quien se preocupe por uno mismo, porque la información existe y es un tema que todo mundo conoce. El que no quiere usarla es porque no quiere."

"Platicando más con familiares, porque generalmente no hay comunicación y confianza con los padres."

"Hacer mejores campañas donde se muestren las consecuencias de lo que le puede pasar al enfermo y hacerlas más llamativas para los jóvenes, además de difundir la información en los lugares más alejados y marginados."

"Que los mismos jóvenes seamos los que dispersemos la información."

Los entrevistados coincidieron que deberían hacerse campañas enfocadas en darles información a los padres y no sólo darles folletos a los jóvenes,

"Nadie se va a poner a leer un folleto y más si tiene muchas letras."

"Con campañas, pero que también estén dirigidas a los padres de los jóvenes, porque es a ellos a los que los hijos les tienen más confianza."

"Eliminar el tabú de hablar de sexo y Sida, porque si hablas de esto y te informas lo puedes prevenir."

"Favoreciendo la comunicación entre padres e hijos. Lo que yo sé lo aprendí sola o de la tele o de lo que he leído, porque de este tema no puedo hablar con mis papás."

"Hacer las campañas más reales y más frecuentes, porque vemos más campañas publicitarias de juguetes o cosas que no tienen la menor importancia."

¿Crees que los programas de prevención llevados a cabo por el personal de salud de tu comunidad y/o tu escuela disminuyen la posibilidad de que los jóvenes adquieran la infección por VIH?

La mitad de los jóvenes opinaron en sentido positivo y sus argumentos eran: mientras más informado estés, más armas vas a tener en el momento de tomar una decisión que puede marcar tu vida. Un porcentaje similar estaba en contra y sostenía que nunca o casi nunca había escuchado o estado en contacto con algún programa que les informara de la prevención del Sida. Opinaron que depende de que la persona esté interesada o no en el tema y consideraron que no todos tienen acceso a la información o las campañas.

"No, porque no causan impacto en nosotros, nos lo dicen y $X$."

"Sí, en algunos casos. Yo, por ejemplo, antes de entrar en la escuela no tenía suficiente información."

"Sí, porque brindan la información, pero no pueden vigilar lo que nosotros hacemos, mientras más información nos proporcionen, más herramientas vamos a tener para decidir."

"Sí, al final la última decisión la tienes tú, pero si tienes información vas a pensar un poco más sobre lo que vas a hacer."

Vol. 17/No. 3/Julio-Septiembre, 2006 


\section{Vera-Gamboa, F Sánchez-Magallón, RA Góngora-Biachi}

Si ahora te enteraras que tienes la infección por VIH, ¿cómo te sentirías?

La primera y más frecuente respuesta expresada por el total de los jóvenes fue que nunca habían pensado estar en tal situación. Las primeras emociones serían de tristeza, decepción, depresión, frustración, ira, ganas de morir, miedo, desilusión, decepción y trauma, según respondieron el total de los entrevistados. Posteriormente, algunos sentirían aceptación y tratarían de cambiar a una actitud más positiva de superación y colaboración con otras personas que tuvieran el mismo problema. Sin embargo, otra parte pensó en suicidarse (11\%), porque su problema ya no tendría solución.

\section{¿Qué podrías hacer por las personas que tienen VIH/Sida?}

La mayoría de los entrevistados coincidió en no discriminarlos y darles apoyo moral (62/72) Los menos sugirieron apoyarlos con víveres o de manera económica dentro de sus posibilidades. Uno se mostró indiferente si no era una persona allegada a él y sugirió que lo mejor sería que se muriera. Se percibía cierto temor a infectarse por contacto casual con una persona por el VIH, aunque conocían las formas de transmisión.

"No rechazarlas, no negarles oportunidades y apoyarlas en lo que se pueda".

"Darles apoyo moral, pero si me daría un poquito de miedo el poder contagiarme".

"Tratar de que la relación sea igual, pero es difícil, tal vez por instinto me alejaría."

"Si es una persona con la que me llevo, tratarlo en la forma que lo trataba, sin discriminarlo, le daría ánimo y lo apoyaría. Pero si no lo conozco, la verdad, sería mejor que se muriera."

\section{¿Como joven, ¿qué te gustaría hacer en tu comunidad para prevenir el Sida?}

Un pequeño grupo de jóvenes (7/72) ya está participando haciendo carteles y recolecta de víveres para personas infectadas por el VIH, pero mencionaron que lo más importante es crear conciencia para apoyar a estas personas y educar

\section{Revista Biomédica}

a las que se encuentran a su alrededor, ya que son con las que más contacto tienen y mayor influencia pueden ejercer para poner su granito de arena en lograr una mejor calidad de vida para las personas infectadas por VIH.

\section{DISCUSIÓN.}

De acuerdo a los resultados del estudio, se pudo determinar que muy cerca del total (98\%) de los encuestados, indistintamente de su grado escolar y sexo, presentaron conocimientos adecuados y suficientes sobre el Sida. Estos datos son similares a lo reportado por Esquivel-Alcocer (1) en su estudio en estudiantes de preparatoria de la misma universidad. Sin embargo, CastroSansores, et al., en la misma universidad (11), encontraron que sólo el $36.4 \%$ de los alumnos tenía un conocimiento preciso del Sida en relación al diagnóstico, sintomatología y tratamiento. Es importante señalar que este estudio fue aplicado en estudiantes de primer año de licenciatura, con una edad promedio de 20 años

En cuanto a las formas de transmisión del Sida, la encuesta reveló que el 9\% presentó conocimientos equívocos de las formas de transmisión, resaltando el hecho. Este resultado varía considerablemente del estudio de CastroSansores, et al. (11), donde el $25.4 \%$ tenía conceptos equívocos con respecto a la transmisión, lo que sugiere que en cuanto a conocimiento de las formas de transmisión ha habido una mejoría, particularmente considerando las diferentes poblaciones estudiantiles (bachillerato y licenciatura). Sin embargo, aún persiste la idea de otras formas de transmisión, situación que va más en relación a la actitud y al temor ante esta enfermedad, y coincide con el estudio de Egger en estudiantes de secundaria, en Nicaragua (14). Hay que mencionar también el hecho de que la quinta parte de los entrevistados no consideró el sexo oral como mecanismo de transmisión.

A nivel cualitativo, los jóvenes coincidieron en que la información es la piedra angular de este problema y que las campañas deben darse con 


\section{Conocimientos y percepción de riesgo sobre el Sida en estudiantes}

mayor frecuencia y proporcionar información concreta, de forma llamativa para los jóvenes, atendiendo las necesidades o gustos del grupo al que va dirigida. Además, solicitaron que las campañas deben de ser promovidas por iconos o gente que los jóvenes admiren o por otros jóvenes y deben incluir testimonios e imágenes que les hagan tomar conciencia de los estragos que puede producir la enfermedad. La educación de pares fue reconocida por los jóvenes como la mejor manera de difundir la información.

Se encontraron mitos sobre el Sida, como fueron el temor a la infección por el VIH a través de mosquitos o fomites. En cuanto a la sexualidad, la presencia de estereotipos de género y el tan frecuente mito de que con condón "no se siente igual”.

Existe una baja percepción de riesgo para la infección, en especial porque la mayoría de ellos no lleva una vida sexual activa, situación que dificulta la labor de prevención.

En lo que respecta al comportamiento sexual, en nuestro estudio $15 \%$ de los encuestados ya habían tenido relaciones sexuales, a la edad promedio de 17 años, edad muy similar a la reportada en estudios previos, incluyendo la Encuesta Nacional de Juventud (15). En general se presentó en los estudiantes una actitud favorable ante las personas que viven con VIH/Sida, aunque en el aspecto cualitativo fue interesante encontrar temor ante el contacto o uso de fomites. Es pertinente señalar que fueron los mismos jóvenes quienes se hicieron este cuestionamiento durante las entrevistas de grupos focales.

En lo que respecta al uso del condón, más de la mitad de los adolescentes con vida sexual activa refirieron haberlo utilizado, y de éstos, el $65 \%$ lo utilizó como método anticonceptivo exclusivamente, hecho que llama la atención, ya que es sugerente de que los jóvenes están más preocupados por evitar un embarazo que el Sida pasa a un plano secundario. Esta situación nos debe hacer reflexionar acerca del porqué esto ocurre. Esto puede deberse a que se enfatiza más el uso de este método como método de planificación familiar y no tanto como medida de prevención para el VIH o, como ya se ha señalado, existe en esta etapa del ciclo vital mayor preocupación por un evento próximo -como es el embarazo- y no algo que los jóvenes ven lejano -como es la infección por VIH-, ya que durante las entrevistas focales, los jóvenes señalaron repetidamente que ellos viven el momento. Las situaciones anteriores idealmente deberán ser tomadas en consideración en la implementación de acciones para la prevención del VIH/Sida en la población juvenil.

\section{REFERENCIAS.}

1.- Esquivel-Alcocer L, Casanova-Quiñónez G, Uc-Aké N. Conocimientos De la sexualidad en estudiantes de preparatoria. Educación y Ciencia 2001; 5:41-52.

2.- Burgos-Fajardo R. Sexualidad y Adolescencia: hacia una educación familiar integral. Educación y Ciencia 1997; 1: 27-33.

3.- Flores-Galaz M, Mendoza-Mejía R. EL SIDA: su percepción de riesgo de contagio en estudiantes universitarios. Educación y Ciencia 2001; 5: 53-66.

4.- UNAIDS/WHO. AIDS Epidemia update: December 2000. Geneva: UNAIDS, WHO. Disponible en: www.unaids.org Citado Marzo 2003.

5.- ONUSIDA. Resumen mundial de la epidemia de VIH/ SIDA. Diciembre 2003. Disponible en www.unaids.org Citado Diciembre 2003.

6.- Idemyor V. Promising microbicide approach for prevention of human inmodeficiency virus transmission needs more support. Pharmacotherapy 2002; 22:1074-6.

7.- Martínez-Ramírez A, Villaseñor-Farías M, Celis de la Rosa A. El condón masculino y su eficacia. Información y creencias en adolescentes escolares. Rev Med IMSS 2002; 40:35-41.

8.- Micher J, Silva J. Nivel de conocimientos y prácticas de riesgo para enfermedades de transmisión sexual. Sida/ETS 1997; 3:68-73.

9.- CONASIDA. Epidemiología del VIH/Sida en México 


\section{Vera-Gamboa, F Sánchez-Magallón, RA Góngora-Biachi}

en el año 2003. Centro Nacional para la Prevención y Control del VIH/Sida. Secretaría de Salud. Disponible en: www.salud.gob.mx/conasida Citado Enero 2004.

10.- Epidemiologia del Sida Diciembre 2004. Dirección General de Epidemiología. Secretaría de Salud. Disponible en: www.salud.gob.mx/conasida Citado Diciembre 2004.

11.- Castro-Sansores C, López-Avila M, Góngora-Biachi RA. Conocimiento e Impacto de tres medios de enseñanza en relación al Síndrome de Inmunodeficiencia Adquirida en estudiantes universitarios. Rev Biomed 2000; 11:7-16.

12.- MacQueens. Enriquecimiento de los hechos y las cifras. Network en español 2002; 22:4.

13.- Pope. Disponible en: La técnica de recolección de información mediante los grupos focales. http: //huitota.udea.edu.co/"cco/artículos/grupos focales.html. Citado Mayo 2004.

14.- Egger M, Ferrie J, Gorter A, González S, Gutiérrez R, Pauw J, et al. Conocimientos, actitudes y prácticas acerca del SIDA entre estudiantes de escuelas secundarias de Managua. Bol Of Sanit Panam 1994;117: 12-21.

15.- Pérez-Islas JA. Encuesta Nacional de Juventud 2000. Instituto Mexicano de la Juventud. Disponible en: www.imjuventud.gob.mx Citado: Abril 2004.

\section{Revista Biomédica}

